Dossiê: Imaginário e Diálogo Inter-religioso -Artigo Original (c) (1)

\title{
Diálogo inter-religioso: \\ perspectivas a partir de uma teologia protestante
}

\author{
Interfaith dialogue: perspectives from a protestant theology
}

Carlos Ribeiro Caldas Filho*

\begin{abstract}
Resumo
A questão do diálogo inter-religioso (DIR) tem sido uma questão de fronteira na teologia, pelo menos desde as últimas cinco décadas do século passado. Diferentes possibilidades teóricas de abordagem da questão têm sido propostas. Destas, as mais conhecidas são a reação contra o diálogo, o exclusivismo, e as duas favoráveis, o inclusivismo e o pluralismo. Neste sentido, são notáveis as contribuições de teólogos católicos ocidentais, sejam estes europeus, como Claude Geffré, Jacques Dupuis e Karl Rahner; estadunidenses como Roger Haight e Paul Knitter; brasileiros como Faustino Teixeira e Roberlei Panasiewicz; ou os asiáticos, como Michael Amaladoss, Raimon Panikkar, Tissa Balasurya e Aloysius Pieris. A literatura a respeito no Brasil tem contemplado mais esta produção católica, e não se tem refletido muito a respeito da contribuição protestante sobre esse tema. Por isso, o presente artigo pretende contribuir para o debate ao apresentar algumas contribuições a respeito do diálogo inter-religioso e a sua prática, a partir da teologia protestante.
\end{abstract}

Palavras-chave: Diálogo inter-religioso; Teologia protestante contemporânea; Conselho Mundial de Igrejas; Teologia das religiões.

\begin{abstract}
Interfaith dialogue (IFD) has been a border issue in theology at least in the last five decades of the last century. Different theoretical possibilities of approaches to such a question have been raised, e.g., exclusivism, inclusivism and pluralism. Therefore, there are remarkable contributions to this from a Catholic perspective, by Westerner theologians: Europeans (e.g., Claude Geffré, Jacques Dupuis and Karl Rahner), Americans (e.g., Roger Haight and Paul Knitter), Brazilians (e.g., Faustino Teixeira and Roberlei Panasiewicz) and by Asians alike (inter alia, Michael Amaladoss, Raimon Panikkar, Tissa Balasurya and Aloysius Pieris). Technical literature in Brazil has its focus mainly on this Catholic contribution. As a consequence, not much about the Protestant understanding of the theme has been said. Therefore, this article intends to present some Protestant contributions to the theory (and practice) of interfaith dialogue.
\end{abstract}

Keywords: Interfaith dialogue; Contemporary Protestant Theology; World Council of Churches; Theology of Religions.

Artigo recebido em 15 de janeiro de 2017 e aprovado em 28 de março de 2017.

* Doutor em Ciências da Religião pela Universidade Metodista de São Paulo (2000). Professor do Programa de Pós-Graduação em Ciências da Religião da PUC Minas. País de Origem: Brasil. E-mail: crcaldas2009@hotmail.com.

Horizonte, Belo Horizonte, v. 15, n. 45, p. 112-133, jan./mar. 2017 - ISSN 2175-5841 


\section{Introdução}

O presente artigo seguirá o seguinte roteiro:

1) Conceituação de diálogo inter-religioso

2) O estado da arte da pesquisa a respeito no Brasil

3) Contribuições protestantes ao tema do diálogo inter-religioso

Na primeira parte, será apresentada, ainda que em síntese, e em perspectiva crítica, o que se entende por diálogo inter-religioso (doravante, DIR), e as principais linhas teóricas de abordagem ao tema: o exclusivismo, o inclusivismo e o pluralismo.

A seguir, ao apresentarem-se as pesquisas a respeito no Brasil tentar-se-á comprovar a hipótese operacional do artigo, qual seja, que a produção acadêmica brasileira sobre o tema tem concentrado sua atenção nas contribuições católicas, e em grande medida, deixado de lado as contribuições protestantes. Talvez este "esquecimento" seja opção metodológica, ou seja, a deliberação consciente de se fazer um recorte e concentrar a atenção nas elaborações sobre o DIR que são produto da reflexão crítica de pensadores católicos. Tal expediente sem dúvida é legítimo. Sem entrar no mérito da questão, o presente artigo não pretende apresentar um contraponto propriamente. Antes, se propõe a fazer um complemento a esta perspectiva que tem sido a dominante na literatura especializada no Brasil até o momento.

Por fim, o fechamento do texto apresentará, também em perspectiva crítica, algumas contribuições protestantes relevantes quanto ao tema. A apresentação destas contribuições poderá enriquecer e adensar o debate.

\section{0 que é diálogo inter-religioso}

O DIR não deve ser confundido com diálogo ecumênico nem com diálogo intercredal. Neste sentido, uma distinção simples, mas útil, é a apresentada pelo Escritório de Questões Ecumênicas e Inter-Religiosas da Arquidiocese de Chicago (ARCHDIOCESE OF CHICAGO, 2017). Serão apresentadas as distinções elaboradas 
pela Arquidiocese de Chicago, seguidas de detalhes históricos e observações críticas:

- Diálogo ecumênico é o diálogo e o esforço conjunto vivenciado intramuros, no seio da fé cristã̃ . O principal órgão de esforço ecumênico em nível mundial é o Conselho Mundial de Igrejas, World Council of Churches - WCC em inglês (doravante, CMI), organizado em 1948 em Amsterdam, com escritório central em Genebra, Suíça. Atualmente o CMI conta com 348 igrejas-membro, incluindo neste rol igrejas protestantes, anglicanas, independentes africanas, pentecostais e ortodoxas orientais autocéfalas (a Igreja Católica Apostólica Romana participa apenas como observadora, não sendo membro da entidade (WCC, 2017). A Declaração Conjunta Luterano-Católica Romana sobre a Doutrina da Justificação pela Fé, de 1999 (subscrita pela Conferência Metodista Mundial em 2005) é talvez o mais notável exemplo recente de esforço ecumênico visando um testemunho comum da fé cristã ${ }^{2}$.

- Diálogo intercredal é o diálogo - ou melhor, triálogo - envolvendo os três credos monoteístas da tradição abraâmica, a saber, judaísmo, cristianismo e islamismo. Claude Geffré (n. 1926), teólogo dominicano francês, especialista no tema da teologia das religiões, refletindo a respeito de temas possíveis para a conversação neste triálogo, extraídos da herança teológica comum a estes credos, sugere três possibilidades: "o respeito do humano autêntico, o combate pela justiça, a salvaguarda da criação” (GEFFRÉ, 2013, p. 253-259).

- Diálogo inter-religioso, o tema propriamente do presente artigo, é o mais ousado, por assim dizer, e o mais difícil, pois envolve a conversação entre tradições religiosas que não compartilham uma raiz comum (como no caso do diálogo intercredal). Logo o DIR envolve relacionamentos entre expressões religiosas tão diferentes como o cristianismo, o hinduísmo e o budismo. O pressuposto básico do DIR é a crença na possibilidade do mysterium salutis da

\footnotetext{
${ }^{1}$ É vasta a bibliografia sobre ecumenismo, movimento ecumênico e diálogo ecumênico. Para não se incorrer em fuga do tema, não se entrará em discussão detalhada a respeito. Não obstante, remeter-se-á apenas a uma obra, alentada e ampla em seu escopo, que pontua questões históricas e teológicas a respeito: (LOSSKY, Nicholas; MIGUEZ-BONINO, José; POBEE, John; STRANSKY, Tom; WAINWRIGHT, Geoffrey; WEBB, Pauline, 2002).

${ }^{2}$ Para detalhes sobre a Declaração Conjunta sobre a Doutrina da Justificação consultar (CALDAS FILHO, 2016).
} 
parte do Deus Criador operar para além dos limites institucionais do cristianismo. A admissão desta possibilidade deu azo ao desenvolvimento de uma vertente diferente do pensamento teológico, a teologia das religiões. Nas palavras do já mencionado Geffré,

A tarefa histórica da teologia consiste em refletir sobre a inscrição do Absoluto do mistério de Cristo nas outras tradições religiosas, não só no cristianismo, e em repensar de novo a relação entre a Igreja visível e o Reino de Deus (GEFFRÉ, 2013, p. 31).

Geffré chega a afirmar que o pluralismo religioso se constitui em um novo paradigma para a teologia. Sendo o DIR o foco do presente artigo, faz-se necessário dar-lhe apresentação pouco mais ampliada. Na literatura especializada está consagrada pelo uso a distinção entre as três principais correntes ou modelos de compreensão deste diálogo: o exclusivismo, o inclusivismo e o pluralismo.

O exclusivismo foi o modelo dominante na maior parte da história do cristianismo, e ainda hoje é o que predomina na maior parte dos círculos cristãos, católicos, protestantes e ortodoxos 3 . Entende que o cristianismo é o único caminho de salvação. No caso do catolicismo romano, o exclusivismo parte de uma aplicação - equivocada, diga-se de passagem - do conhecido dito de Cipriano de Cartago, um dos Pais (Padres) Latinos da Igreja, do século terceiro da era cristã, que, comentando sobre os que ameaçavam abandonar a igreja, afirmou que extra ecclesiam nula salus - "não há salvação fora da igreja”. Sendo Cipriano um dos Pais Ante-Nicenos, um pensador pré-constantinianismo, não é razoável admitir que ele tenha pensado em termos de igreja enquanto instituição. Antes, a expressão de Cipriano refere-se à igreja enquanto corpo místico de Cristo, a Communio fidelium, aqueles que misteriosamente participam da Communio sanctorum. Em suma: o exclusivismo diz: “a minha religião é a única certa, a única verdadeira”.

No meio protestante o exclusivismo recebeu forte influência da teologia de Karl Barth (1886-1968), que, em seu programa de crítica ao liberalismo teológico

\footnotetext{
${ }^{3}$ É curioso que a literatura especializada tenha praticamente cristalizado apresentar o exclusivismo como uma possibilidade de DIR. Na verdade, incluir o exclusivismo como possibilidade de DIR é uma virtual contradição de termos, visto que no exclusivismo não há diálogo... Logo, a rigor, o exclusivismo não é uma possibilidade do DIR. Antes, é uma reação a este.
} 
protestante, no qual fora formado, resgatou a teologia do reformador francês João Calvino (1509-1564), relendo-a conforme as categorias do início do século passado. A teologia liberal protestante é fortemente antropocêntrica em seus fundamentos. Reagindo contra este antropocentrismo, Barth, ecoando Calvino, dá forte acento à transcendência de Deus, entendido como Das Andere, o Totaliter aliter, isto é, o“totalmente outro", que se nos revela na pessoa de Jesus Cristo. Logo, toda religião é um projeto falido, fadado ao fracasso, pois é esforço humano para se achegar a Deus. A despeito da ressalva feita por Von Sinner (2007, p. 121), que a posição do teólogo da Basileia quanto às outras religiões não era tão fechada como em geral se pensa, a teologia da revelação de Barth não permite espaço para se pensar em outros termos que não sejam os do exclusivismo religioso. Pois em seu programa teológico, Barth contrasta revelação e religião: o cristianismo é o depositário da revelação de Deus em Cristo, enquanto a religião nada mais que a tentativa humana de operar sua própria salvação4.

O inclusivismo é um pouco mais aberto, e é uma opção mais recente. O inclusivismo admite a possibilidade que, pelos muitos e misteriosos caminhos de Deus, a salvação aconteça fora e além dos limites do cristianismo. O resumo da posição inclusivista é: "as outras religiões são boas, mas a minha é a melhor”. No caso da teologia católica contemporânea, há pelo menos duas vertentes identificadas com o paradigma inclusivista: a assim chamada "teologia do acabamento", defendida por teólogos como Jean Danielou, Henri de Lubac e Hans Urs Von Balthasar: as religiões são boas, mas encontram seu "acabamento", seu "aperfeiçoamento" ou "remate" no cristianismo (TEIXEIRA, 2010). A outra, talvez a mais eloquente expressão de inclusivismo, é a apresentada na teologia de Karl Rahner (1904-1984), com sua famosa tese dos “cristãos anônimos". Rahner parte de uma teologia da graça: toda salvação é dom gratuito, escandaloso e misterioso da graça de Deus. A graça antecede a experiência da salvação. Mais que isto, a graça antecede a própria busca pela salvação. O ser humano busca o que Rahner chama de "existencial sobrenatural”, e a busca em si já é iniciativa da graça divina em

${ }^{4}$ Para detalhes da posição de Barth quanto ao DIR consultar CHUNG (2001, p. 232 ss); BARRA (2014, p. 156-160). 
atuação no coração humano. A teologia de Rahner tem raiz remota no conceito de logos spermatikos , a semina Verbi, "semente do Verbo", de Justino, o Mártir (10o165): em todas as culturas do mundo há centelhas, fagulhas da "verdadeira luz que, vinda ao mundo, ilumina a todo homem" (João 1.9) (SEMINA VERBI, 2009). Outro elemento decisivo no pensamento de Rahner é sua compreensão da doutrina da graça, e também seu entendimento de textos como 1 Timóteo 2.4: "Ele (Deus) quer que todos sejam salvos e venham a conhecer a verdade" (Nova Tradução na Linguagem de Hoje), Rahner desenvolve sua teoria que não será a pertença institucional ao corpus christianum que definirá a vivência da salvação (RAHNER, 1971, p. 102-103). A posição inclusivista de Rahner foi, por um lado, bastante influente, mas ao mesmo tempo, recebeu (e recebe) muitas críticas. Esta visão tem o "mérito" de desagradar tanto exclusivistas mais tradicionais como pluralistas não conservadores. Para o exclusivista, a visão de Rahner é muito aberta, e para o pluralista, não é tão aberta quanto deveria ser... Outro ponto apresentado contra a tese rahneriana é a inversão do argumento: se há “cristãos anônimos”, pode haver também “muçulmanos anônimos” ou "budistas anônimos”. Mas não há dúvida que o ponto de vista inclusivista é um avanço, por assim dizer, em relação ao exclusivismo. Resumindo: na visão inclusivista "todas as religiões são boas, mas a minha é a melhor".

O pluralismo por sua vez parte do pressuposto que "todas as religiões são igualmente boas”. Esta compreensão tem sido desenvolvida por vários teólogos católicos contemporâneos. Um destes é o catalão de origem indiana Raimon (algumas vezes seu nome aparece grafado na forma portuguesa Raimundo) Pannikkar (1918-2010) que, desde a década de 1960, com sua tese de doutorado sobre o "Cristo desconhecido do Hinduísmo" (1981) tem proposto que o Cristo é o mediador entre Deus e o mundo, e que este Cristo é conhecido, por muitos e diferentes nomes, por fieis de todas as religiões (PANIKKAR, 1971a; 1971b). Outro é o estadunidense Paul Knitter (n. 1939). Autor prolífico, Knitter (2010) rebate um argumento muitas vezes usado contra os opositores das posições inclusivista e pluralista, que estas significariam o fim da missão evangelizadora cristã. Knitter 
argumenta que uma visão pluralista não necessariamente implicará na morte da missão cristã. Antes, redefine e revisa o conceito de missão, apresentando-a em termos de diálogo "globalmente responsável” (KNITTER, 2010, p. 131-188). Na mesma linha está o já mencionado Geffré, que no contexto católico, tendo como pano de fundo remoto a partir da Declaração Conciliar Nostra aetate - A declaração das relações da Igreja com as religiões não cristãs - de 1965, que afirma que a Igreja (Católica) deve aceitar o que há de "bom e santo" nas outras religiões, procura desenvolver um projeto de teologia das religiões tríplice em seus objetivos: 1) Compreender o sentido da evolução da teologia das religiões nos últimos quarenta anos5; 2) Explicar teologicamente a razão do pluralismo religioso e assim fornecer um fundamento teológico para o diálogo inter-religioso encorajado pela Igreja depois do Vaticano II e, finalmente, 3) Manifestar a oportunidade do diálogo inter-religioso para uma melhor inteligência da singularidade do cristianismo como religião do Evangelho (GEFFRÉ, 2013, p. 6-7).

\section{O estado da arte atual da pesquisa sobre o DIR no Brasil}

Tendo apresentado, em síntese, o que se entende por DIR, e seus três principais paradigmas, partir-se-á agora para uma apresentação do status questionis da pesquisa a respeito no Brasil. Desnecessário dizer que tanto este ponto do artigo como o próximo pretendem apresentar o momento atual da pesquisa no Brasil, todavia, sem pretensão de exaustividade. Não existe a intenção de apresentar um panorama completo com tudo que foi publicado a respeito no país. Tal pretensão foge por completo aos objetivos do artigo.

A pesquisa produzida por teólogos católicos a respeito do DIR, no Brasil e no mundo, nos últimos 50 anos, é resultado, influência e consequência do já mencionado documento Nostra Aetate, do Vaticano II. A partir daí, inúmeros teólogos passaram a dedicar sua atenção ao tema. Alguns destes o fizeram a partir de sua experiência missionária em contextos nos quais o cristianismo é minoria. É

\footnotetext{
${ }^{5}$ Este texto de Geffré é de 2005. O livro do qual foi extraído, publicado no Brasil em 2013, é coletânea de textos do mesmo autor, publicados originalmente em diferentes periódicos.
} 
este o caso, por exemplo, do teólogo jesuíta franco-belga Jacques Dupuis (19232004), que atuou como missionário de carreira na Índia (de 1948 a 1984). Dupuis foi um dos pioneiros, e ao mesmo tempo, um dos mais ousados pensadores neste campo, ao sugerir em Verso una teologia Cristiana del pluralismo religioso (DUPUIS, 1999) a possibilidade que a salvação de Deus aconteça também fora dos limites do cristianismo. Dupuis recebeu uma notificação da Congregação para a Doutrina da Fe do Vaticano por conta das afirmações de seu livro (CONGREGAÇÃO PARA A DOUTRINA DA FÉ, 2001).

A menção a Dupuis se justifica por ter sido ele o mentor intelectual do principal teórico da teologia do pluralismo religioso no Brasil e do DIR. Trata-se do Professor Faustino Luis do Couto Teixeira, pesquisador de longa data do tema, e, consequentemente, com vasta produção a respeito (inter alia, 1993, 1997, 2012, 2014, sem embargo de artigos publicados sobre o tema pelo menos desde 1995) ${ }^{6}$. Teixeira é um dos primeiros a falar de teologia das religiões e de DIR no contexto brasileiro. Em sua longa carreira como professor universitário, como se verifica em seu Lattes, em nível de graduação e de pós-graduação, no Programa de PósGraduação em Ciência da Religião da Universidade Federal de Juiz de Fora, desde 1992, especificamente sobre o tema do DIR, já ministrou 95 palestras, em eventos no Brasil e no exterior, orientou 11 dissertações de mestrado, seis teses de doutorado e três monografias de conclusão de curso, além de no momento estar a orientar uma tese de doutorado. O Professor Teixeira também tem ministrado disciplinas como Diálogo inter-religioso, Teologia do pluralismo religioso, Religião e diálogo, Teologia das religiões e Questões especiais de teologia das religiões, tanto no seu programa de origem, como também no Programa de PósGraduação em Ciências da Religião da PUC Minas, na condição de professor visitante (em 2008). E a vastidão desta produção indica a paixão do Professor Teixeira pelo tema, qualificando-o sem dúvida como uma das maiores autoridades no tema do DIR no Brasil. Graças a tal labor acadêmico intenso obras de teólogos

\footnotetext{
${ }^{6}$ Evidentemente a observação a respeito da trajetória acadêmica do Professor Faustino Teixeira focaliza especificamente o que em sua produção se refere ao DIR.
} 
católicos contemporâneos importantes no campo da teologia das religiões e do pluralismo religioso têm sido divulgadas no Brasil, como Jacques Dupuis e Claude Geffré. Sua atuação "fez escola”, por assim dizer, se levar-se em conta que algumas pesquisas de seus “discípulos” foram publicadas (inter alia, PANASIEWICZ, 2010). Esta numerosa produção tem concentrado o foco nas origens, influxos, notas distintivas de diferentes teólogos e possibilidades teóricas para outras pesquisas sobre o DIR no horizonte da teologia católica contemporânea.

A pesquisa sobre o DIR no Brasil também tem sido enriquecida com a publicação de obras de outros teólogos católicos contemporâneos (inter alia, AMALADOSS, 2005; PIERIS, 2008; KNITTER, 2010).

Há também que se mencionar a divulgação do DIR levada a cabo pelo Instituto Humanitas (IHU) da Universidade do Rio dos Sinos (UNISINOS), de São Leopoldo (RS). Uma pesquisa sobre “diálogo inter-religioso" realizada no site da mencionada instituição em janeiro de 2017 indicou 3.820 resultados. São artigos e entrevistas sobre o tema, que se constitui em rico e abundante material de pesquisa de grande utilidade para qualquer estudioso do DIR no Brasil.

Uma característica que domina todos estes esforços de divulgação do e reflexão sobre o DIR no Brasil é o olhar voltado predominantemente para as produções de corte católico. Pouco se tem mencionado sobre a contribuição de acento protestante ao tema. Esta afirmação conduz ao próximo ponto do presente artigo.

\section{Contribuições protestantes ao tema do diálogo inter-religioso}

Se a reflexão católica sobre o DIR tem sua gênese na abertura do Vaticano II, a partir do documento Nostra Aetate, a teologia protestante a respeito, por não ter um organismo que aglutine e centralize suas ações em nível mundial, teria que obrigatoriamente partir de iniciativas de pensadores individuais. Neste sentido, uma das contribuições pioneiras foi a do teólogo luterano germano-americano Paul Tillich (1886-1965). Durante seu período de docência na Universidade de Chicago, 
tendo como colega o conhecido historiador das religiões romeno Mircea Eliade (1907-1986), propôs a formulação de uma teologia com base na revelação universal de Deus na história das religiões (BRAATEN, 1986, p. 27). Já em 1963 Tillich afirmou:

Devo dizer de novo que uma teologia cristã que não seja capaz de empreender um diálogo criativo com o pensamento teológico das outras religiões perde uma ocasião histórica mundial e permanece provincial (apud GEFFRÉ, 2013, p. 5).

Em 1960 Tillich fez uma viagem ao Japão, lá permanecendo de 3 de maio a 10 de julho. Neste período, palestrou, e teve contato e diálogos com mestres budistas e xintoístas (na cidade de Kyoto). Em um livro recente, o estudioso japonês Tomoaki Fukai recolheu um testemunho do próprio Tillich sobre o impacto que o período passado no Japão lhe causou:

Não consigo expressar o que isto significou antes de todas as impressões que tive; e é provável que outros venham a perceber a influência do Japão mais que eu mesmo. Mas eu sei que algo aconteceu: doravante, não tolerarei mais nenhum provincianismo ocidental do qual tenha consciência, em minha reflexão e na minha obra (TILLICH, apud FUKAI; TOMOAKI, 2013, p. 2, tradução nossa).

Esta experiência vivencial de fato causou impacto em Tillich. Portanto, no final de sua vida, ele expressou seu desejo de reescrever sua teologia sistemática a partir da história das religiões (RIBEIRO, 2000, p. 32; VON SINNER, 2007, p. 120; GEFFRÉ, 2013, p. 87). Interessante observar que um de seus últimos trabalhos versou sobre o significado da história das religiões para a teologia sistemática cristã (TILLICH, 1966, p. 80-94)7. O teólogo metodista brasileiro Claudio de Oliveira Ribeiro, também estudioso do tema do pluralismo religioso, oferece uma sistematização das pressuposições de Tillich para uma teologia das religiões, que, por conseguinte, podem (vir a) ser úteis como marcos teórico-conceituais para o DIR:

1) As experiências da revelação são universalmente humanas;

2) A revelação é recebida pelo ser humano, nas condições de caráter alienado que possui e na situação humana finita e limitada;

\footnotetext{
${ }^{7}$ Em um trabalho recente, RIBEIRO (2013) questiona a tese que em sua última conferência Tillich teria demonstrado abertura para com o pluralismo religioso. Para Ribeiro, Tillich não faz mais que confessar que teria errado em não incorporar a história das religiões em sua teologia sistemática.
} 
3) Em toda a história humana, não há somente experiências revelatórias particulares, mas há um processo revelatório no qual os limites de adaptação e as deficiências de distorção são sujeitas à critica, seja mística, profética ou secular;

4) Há um evento central na história das religiões que une os resultados positivos desta crítica e que nele e sob ele as experiências revelatórias acontecem. Um evento, portanto, que faz possível uma teologia concreta com um significado universal;

5) A história das religiões, em sua natureza essencial, não existe ao lado da história e da cultura. O sagrado não está ao lado do secular, mas ele é a sua profundidade. O sagrado é o chão criativo, e ao mesmo tempo um juízo crítico do secular (RIBEIRO, 2000, p. 34-35; 2014, p. 42-53).

Tillich não compartilha do pessimismo de Barth quanto às religiões. Muito pelo contrário, Tillich vê a busca humana pelo Sublime, pelo Santo, pelo Sagrado, busca esta que assume diferentes formas culturais, como expressão do Ultimate concern (“in-quietude final”, cf. GOUVEA, 2014, p. 93-103) humano, para o qual convergem todas as religiões. Claude Geffré faz uma leitura da contribuição pioneira de Tillich para o DIR e afirma:

Toda a sua [de Tillich] está, de fato, sob o signo da doutrina paulina, ao mesmo tempo cósmica e escatológica, da nova criação. Ele se distancia, assim, do paulinismo dos primeiros reformadores e de Karl Barth, que é a doutrina da justificação pela fé. Ele se inscreve, portanto, de maneira original, na continuidade com a doutrina tradicional dos Padres da igreja sobre o Logos universal e sobre as "sementes do Verbo" espalhadas por toda a criação. E assenta o princípio de toda teologia cristã das religiões. Se Cristo é o absolutamente concreto, então, de certa maneira, o cristianismo como religião particular já está implícito nas outras religiões. E estas são uma manifestação particular do Logos universal (GEFFRÉ, 2013, p. 96).

Certamente há em Tillich muito material que poderá ser explorado para uma reflexão crítica sobre o DIR. É o caso do teólogo luterano alemão Reinhold Bernhardt (2004, p. 58-72) que, a teologia da trindade de Tillich tem potencial para servir de marco teórico para uma teologia - protestante - das religiões. Conforme Bernhardt,

Na abordagem da doutrina da trindade de Tillich, que ele próprio só fez frutificar para uma teologia das religiões em forma de alusões, estão contidos potenciais significativos para a teologia das religiões, como, por exemplo, a acentuação da infinitude, universalidade e incognoscibilidade última do fundamento divino do ser. Segundo seu diagnóstico, no protestantismo essa dimensão do caráter misterioso e abissal de Deus teria passado ao segundo plano devido à acentuação da auto-definição de 
Deus em Jesus Cristo. Tillich contrapõe a isso sua definição do ser-em-si como fundamento e abismo insondável. Em seu pensamento, porém, essa definição - mediada pelo padrão de pensamento da teologia da trindade se associa à ideia da revelação. Dessa maneira, ele não precisa interpretar a relação entre Deus-em-si e Deus-para-nós nos moldes de uma posposição. O Deus-para-nós é o auto-despojamento do Deus-em-si, que, em sua essência, está direcionado para o auto-despojamento (BERNHARDT, 2004, p. 68).

E, como se verá na seqüência, outros teólogos de tradição protestante também ofereceram suas contribuições para o DIR. Um dos mais conhecidos é o inglês John Hick (1922-2012) ${ }^{8}$. Sua posição é indubitavelmente a do pluralismo, e de maneira radical. Influenciado pela distinção kantiana entre númeno e fenômeno, Hick argumenta quanto à (im)possibilidade do ser humano conhecer o Real (o termo genérico que utiliza para designar "Deus”, o Transcendente Último, o Ser-em-si). O númeno, (Das Ding an sich) não pode ser conhecido, apenas pensado. Hick concebe a relação do ser humano com Deus em termos como Kant entendeu a relação entre a mente humana e o mundo. Na perspectiva de Hick, as religiões são o fenômeno, tentativas de se atingir o númeno. A posição de Hick tem sido pesadamente criticada, tanto de uma perspectiva filosófica, como por uma teológica. Não será exagero afirmar que Hick é relativista, entendendo ser impossível conhecer a Verdade. Logo, todo esforço para se atingir o númeno é igualmente válido. O já mencionado Michael Amaladoss tece uma crítica contundente, e bem formulada, a Hick:

Ele [Hick] não reinterpreta dogmas tradicionais cristãos. Ele apenas negaos como "mitos". Ele reduz o cristianismo/ a cristandade a uma teoria ética de amor e companheirismo mútuos. Se ele não leva nenhuma religião a sério em seus próprios termos, eu não vejo como ele pode promover diálogos entre religiões ou pessoas que acreditem nelas e estão prontas a morrer por elas [as religiões]. Apenas os não-crentes virão às suas sessões de "diálogo" [...] Você não promove diálogo inter-religioso se não leva as religiões a sério. A maioria das religiões - cristianismo, hinduísmo, islamismo - não se vêem como meros esforços humanos para conhecer o Real, mas como uma auto-revelação de Deus que chama por respostas. Na verdade, cada religião abre espaço para outras religiões com suas próprias percepções de fé. Isso aconteceu com o cristianismo no século XX. A abertura do cristianismo a outras religiões e ao diálogo não é resultado de uma meta-teoria filosófica como esta do Hick, mas a

\footnotetext{
${ }^{8}$ Quanto à contribuição de John Hick ao debate sobre o DIR, há que se mencionar a pesquisa abrangente feita por BARRA (2014).
} Também sobre Hick, consultar MACHADO (2009). 
convicção de que o Espírito de Deus também está presente e ativo em outras religiões, e que esse Deus tem um plano para todas as pessoas.

Então realmente não penso que o livro [9] seja útil - não apenas aos cristãos, mas para qualquer fiel sério de qualquer religião. Apelará apenas aos intelectuais secularizados que pensam que a melhor forma de promover igualdade é relativizando tudo (IHU, 2012).

Outra contribuição protestante interessante para o DIR é a que tem sido vivenciada pelo movimento ecumênico institucional protestante, desde a Conferência de Edimburgo, em 1910, passando por reuniões anteriores à Segunda Guerra Mundial, até a organização do Conselho Mundial de Igrejas (CMI) em Amsterdam, em 1948. O teólogo metodista cingalês S. Wesley Ariarajah (n. 1941), autor de vasta obra a respeito (ARIARAJAH, 1985, 1991, 1999), expôs de maneira didática a história do envolvimento do movimento ecumênico com o DIR. Nos primórdios desta trajetória, era muito forte a influência de Karl Barth, via o missiólogo reformado holandês Hendrik Kraemer (1888-1965), figura importante do movimento ecumênico. Kraemer, seguindo Barth, entendia o cristianismo como lugar único da revelação de Deus em Cristo. A influência de Kraemer foi decisiva na Conferência Missionária Internacional em Tambaran (Índia) em 1938, e nos anos seguintes. Décadas depois é que o DIR foi assumido pelo CMI. Conforme Ariarajah,

Uma conferência do CMI em Kandy, Sri Lanka, em 1967, foi um marco divisório do início do interesse sério no diálogo inter-religioso como tal no CMI, e como o primeiro envolvimento na discussão ecumênica do Secretariado do Vaticano para Não Cristãos. Em Kandy, Kenneth Cragg desafiou de maneira decisiva a atitude Barth-Kraemer em relação às religiões, que dominara o pensamento protestante nas décadas passadas (ARIARAJAH, 2002, tradução nossa).

O CMI tem produzido documentos que orientam suas igrejas-membro na prática propriamente (e não apenas na teorização) do DIR. O primeiro esforço neste sentido data de 1979, com a publicação de um documento intitulado Guidelines on Dialogue with People of other Faiths and Ideologies ("Orientações para o diálogo com pessoas de outros credos e ideologias"). Este documento fora formulado dois anos antes em uma reunião em Chiang Mai, Tailândia, por um grupo de teólogos protestantes (muitos deles asiáticos) ligados ao CMI. Em 2009 o

${ }^{9}$ A referência feita por Amaladoss é a Hick (2005). 
documento foi revisado e atualizado, e mais uma vez submetido às suas igrejasmembro, com intuito de orientar na prática o povo das igrejas na vivência concreta do DIR (WCC, 2004).

Outra contribuição protestante importante para o DIR é a feita pelo cientista da religião canadense Wilfrid Cantwell Smith (1916-2000), que era membro da Igreja Unida do Canadá (United Church of Canada) ${ }^{10}$. Smith organizou em 1952 o Institute of Slamic Studies ("Instituto de Estudos Islâmicos) da Universidade McGill, em Montreal, o primeiro do gênero em toda a América do Norte (INSTITUTE OF SLAMIC STUDES, 2017). Talvez a obra mais importante de Smith seja O sentido e o fim da religião (SMITH, 2006). Nesta obra, que pode ser enquadrada na perspectiva pluralista do DIR, Smith entende que o cristianismo é uma religião entre várias. Seu objetivo não é nem tanto teórico (como se percebe na abordagem de John Hick), mas de incentivar a busca de uma convivência fraterna e irênica entre adeptos de diferentes tradições religiosas:

Se uma pessoa cristã não conseguir ser, inteligente e espiritualmente, cristã não só em uma sociedade cristã ou em uma sociedade secular, mas também no mundo; se um muçulmano não puder ser um muçulmano no mundo; se um budista não lograr obter um lugar em um mundo em que outras pessoas inteligentes, sensíveis e educadas são cristãs e muçulmanas - se não conseguirmos resolver juntos as questões intelectuais e espirituais colocadas pela religião comparativa, então não vejo como uma pessoa possa ser, de alguma forma, cristã ou muçulmana ou budista (SMITH, 2006, p. 23).

Ainda com respeito à contribuição ao DIR promovida pelo CMI, há que se destacar a colaboração de teólogos de tradição protestante que vivem em contextos onde o cristianismo é minoria. O CMI tem sido um elemento de aglutinação destes teólogos. Dentre estes vários podem ser citados. Poderá parecer contraditório ou incoerente, mas o primeiro que será mencionado não era protestante, nem tampouco católico: o indiano Madathilparampil Mamen Thomas, ou mais simplesmente, M. M. Thomas (1916-1996), que era membro da Malankara Mar Thoma Syrian Church, isto é, a igreja cristã presente há séculos na Índia, produto

\footnotetext{
${ }^{10}$ A Igreja Unida do Canadá foi organizada em 1925, a partir de uma união (indicada no próprio nome da denominação) entre igrejas locais metodistas, congregacionais e presbiterianas.
} 
de trabalho missionário da igreja ortodoxa siríaca ${ }^{11}$. Ele é citado neste artigo como exemplo de teólogo cristão não católico que elaborou uma teologia do pluralismo religioso e advogou o DIR, mas, todavia, é virtualmente ignorado pela literatura técnica produzida a respeito no Brasil. M. M. Thomas foi Moderador do CMI de 1968 a 1975, e foi autor prolífico, sempre com foco cristocêntrico, pensando o contexto político, social e religioso indiano a partir da perspectiva da fé cristã (THOMAS, 1987).

Outro teólogo asiático de tradição protestante (metodista) que tem pensado o DIR e as relações do cristianismo com as tradições religiosas do seu continente é o taiwanês Choan Seng Song (n. 1929), que exerceu papel ativo no Conselho de Educação Teológica do CMI. Naquela que talvez seja sua obra principal, Theology from the Womb of Asia (Teologia a partir do útero da Ásia), Song critica uma teologia cristã feita a partir de moldes eurocêntricos, e defende uma hermenêutica teológica para o contexto asiático produzida levando-se a sério questões contextuais culturais e religiosas asiáticas (SONG, 1986). Song afirma que foi exatamente isto que Jesus fez, em seu contexto do Oriente Médio, e é o que os cristãos na Ásia devem fazer para que produzam uma teologia contextual e socialmente relevante (SONG, 1986, p. 17-18).

Outro teólogo protestante asiático participante do CMI (foi um dos preletores principais na Assembleia do CEMI em Nairóbi, Quênia, em 1975) e envolvido com o DIR foi o japonês Kosuke Koyama (1929-2009), que era membro da Igreja Unida de Cristo (United Church of Christ, uma denominação evangélica de origem estadunidense). Koyama foi missionário cristão na Tailândia, entre populações rurais de tradição budista. Como fruto de sua experiência missionária, Koyama produziu uma obra que reflete um dialogo entre cristianismo e budismo (KOYAMA, 1979, 1999). Koyama propõe uma teologia dialógica, e com

\footnotetext{
11 Os cristãos malabarianos (da região de Malabar, sul da Índia, onde é forte a presença dos "cristãos de São Tomé"), ligados a esta igreja, alegam que ela foi fundada por volta do ano 50 da era cristã por Mar Thoma, isto é, o próprio Tomé, apóstolo de Jesus, citado nos Evangelhos. Observe-se que utilizam a palavra "Mar", que tanto em siríaco como em aramaico significa "Senhor", usada como um título respeitoso. Para detalhes consultar MALANKARA MAR THOMA SYRIAN CHURCH, 2017.
} 
indisfarçável dose de bom humor, propõe que a teologia cristã deve misturar uma pitada de pimenta aristotélica com sal budista (KOYAMA, 1999, p. 56-63).

Kitamori Kazoh (1916-1998) foi outro teólogo protestante japonês que produziu uma teologia cristã que leva a sério o DIR. De acordo com John Thomas Hastings, Kitamori Kazoh, juntamente com o citado Kosuke Koyama, foi um dos principais teólogos protestantes japoneses do século passado (HASTINGS, 2001, p. 445-446). Era membro da Igreja Unida de Cristo no Japão. Pode-se dizer que o envolvimento de Kazoh com o DIR se deu em termos teóricos, no sentido que elaborou uma teologia cristã estabelecendo ligações entre alguns termos da tradição japonesa com elementos cristãos. Seu livro mais conhecido é Theology of the Pain of God ("Teologia do sofrimento de Deus"). O proprio titulo do livro já deixa claro que Kazoh trabalhou a partir de categorias asiáticas, não aristotélicas, que sugerem um Deus impassível. Para Kazoh, o sofrimento existe em Deus não como substancia (outro termo técnico tradicional da filosofia arisotelica), mas como resultado de seu relacionamento com o ser humano (KAZOH, 1965).

Mesmo que breve, há que se mencionar o coreano de origem presbiteriana Yi Jeong Yong (1935-1996). Tal como Kitamori Kazoh, Jeong Yong vivenciou o DIR em termos de construir uma teologia que dialogou com conceitos filosóficos tradicionais do Extremo Oriente, como a relação entre yin e yang. Desta maneira, ele (re)(des)construiu uma teologia cristã clássica, elaborada segundo um modelo de filosofia grega. Outro ponto de contato entre as teologias de Kitamori Kazoh e de Yi Jeong Yong está no acento dado ao sofrimento de Deus (o que é compreensível, quando se lembrar-se que ambos escreveram em contextos budistas). Esta marca no sofrimento divino aponta para um possível ponto de contato entre estas teologias produzidas no Leste da Ásia com a teologia latino-americana que, seguindo caminhos teóricos diferentes, tem enfatizado a solidariedade de Deus em Cristo para com os sofredores do mundo. A grande preocupação de Jeong Yong foi produzir uma teologia contextual multicultural não apenas conforme padrões ocidentais, mas uma que fosse relevante e compreensível para cristãos de contextos 
culturais tão diversos como o coreano e o dos Estados Unidos, pais para onde se mudou depois da Guerra da Coréia (YONG, 1995).

E sobre a reflexão a respeito do DIR no Brasil, qualquer consideração a partir de uma perspectiva protestante não pode deixar de mencionar a contribuição de Rudolf Von Sinner, germano-suíço radicado no país. Em Confiança $e$ convivência. Reflexões éticas e comunitárias (VON SINNER, 2007), coletânea de textos do mesmo autor, Von Sinner apresenta a relação concreta entre ecumenismo e paz (VON SINNER, 2007, p. 69-85), os desafios de uma hermenêutica ecumênica, com ênfase nos teólogos católicos Leonardo Boff e Raimon Panikkar (VON SINNER 2007, p. 87-117), sua própria compreensão do DIR (VON SINNER, 2007, p. 119-131) e um ensaio final sobre igreja em perspectiva ecumênica (VON SINNER, 2007, p. 133-147). Von Sinner contribui para tornar o tema do DIR conhecido entre o meio protestante/evangélico brasileiro, onde ainda predomina uma visão exclusivista a respeito das religiões mundiais. Nas palavras de Von Sinner,

O diálogo implica uma posição própria e uma postura de abertura frente ao outro. Somos de religiões diferentes, de certo modo incomensuráveis. Mas a partir da confiança em Deus que quer salvar a todas e todos, tenho uma base comum - embora bastante vaga - que é a condição da possibilidade da aprendizagem. Eu pressuponho, portanto, que posso aprender algo do outro e da outra. Aqui começa o diálogo, com base na confiança em Deus. Leio minha própria fé e a fé do outro e da outra por essa confiança e penso que nós nos ajudamos mutuamente na aprendizagem sobre Deus e nosso lugar e atuação no mundo, portanto é uma hermenêutica da confiança (VON SINNER, 2007, p. 130, ênfase do autor).

\section{Conclusão}

O caminho do DIR tem desafios, tanto teóricos quanto práticos. A teologia católica, em nível mundial, tem produzido vasta literatura a respeito. A teologia protestante, de igual maneira, também tem feito suas contribuições à compreensão do que significa DIR, e na sua vivência, mais em outras latitudes que no Brasil.

O principal desafio teórico, para católicos e protestantes no que diz respeito ao DIR se encontra no nível teológico: como promover o diálogo sem abrir mão do proprium do cristianismo? Não será pela via da relativização que se conseguirá 
produzir verdadeiramente um diálogo. Quanto a isto, cabem as palavras de Lesslie Newbigin (1909-1998), bispo anglicano inglês que foi missionário de carreira na Índia e que foi um dos primeiros bispos da Church of South India (Igreja do Sul da Índia), uma união de igrejas locais congregacionais, presbiterianas, anglicanas e metodistas que se formou em 1947, logo após a Índia ter logrado sua autonomia política da Grã-Bretanha (CHURCH OF SOUTH INDIA, 2017). Newbigin foi um homem de síntese, não apenas entre tradições diferentes agrupadas debaixo do grande guarda-chuva do protestantismo, mas também quanto ao aspecto teológico propriamente, visto que pode ser descrito teologicamente como sendo a um só tempo progressista e conservador. Após comentar a posição de teólogos destacados no cenário do DIR, como os mencionados John Hick, Hendrik Kraemer e Karl Rahner, Newbigin afirma sua própria compreensão a respeito:

A posição que descrevi é exclusivista no sentido de que afirma a verdade ímpar da revelação em Jesus Cristo, mas não é exclusivista no sentido de negar a possibilidade da salvação do não cristão. É inclusivista no sentido de que se recusa a limitar a graça salvífica de Deus aos membros da igreja cristã, mas rejeita o inclusivismo que considera as religiões não cristãs como meios de salvação. É pluralismo no sentido de reconhecer a obra da graça de Deus na vida de todos os seres humanos, mas rejeita um pluralismo que nega a singularidade e o caráter decisivo do que Deus fez em Jesus Cristo (NEWBIGIN, 2016, p.234-235).

O desafio prático quanto ao DIR se manifesta de diferentes maneiras. Líderes eclesiásticos cristãos, protestantes e/ou católicos, talvez não se sintam confortáveis com seus fieis participando de atividades religiosas com fieis de outros credos. Afinal, o cristianismo é herdeiro de uma tradição missionária, nasceu com vocação globalizante (isto é, tem o espírito missionário “em seu DNA”), o que gera muita dificuldade em admitir a possibilidade que o dom da graça de Deus se manifeste em outras tradições. Cristãos que vivem em terras nas quais o cristianismo é minoria e/ou onde, talvez exatamente por isso mesmo, sofre perseguição, podem não se sentir à vontade com alguma prática do DIR. E líderes destas religiões nestes países talvez não vejam necessidade de abertura para diálogo com cristãos, visto serem a maioria nestas sociedades. Não obstante estas dificuldades, o DIR vai se tornar cada vez mais necessidade em um mundo que, 
graças aos avanços da tecnologia de comunicação em tempo real, e por força de movimentos migratórios, se torna cada vez menor.

Concluindo esta breve reflexão, citar-se-á mais uma vez Claudio Ribeiro:

Os objetivos dessa nova movimentação teológica e pastoral, em linhas gerais, residem na articulação dos elementos fundantes da teologia latinoamericana - como a sensibilidade espiritual com a defesa da vida, dos direitos humanos e da terra, especialmente os dos empobrecidos - com uma visão ecumênica, dialógica e de busca de uma fundamentação teológica do pluralismo religioso. Um longo e árduo caminho está ainda por ser trilhado (RIBEIRO 2014, p. 149).

\section{REFERÊNCIAS}

A BÍBLIA SAGRADA. Trad. de João Ferreira de Almeida. London: R.E.A. Taylor, 1819.

ARCHDIOCESE OF CHICAGO. Office for Ecumenical and Inter-Religious Affairs. Archdiocese of Chicago. Disponível em:

<https://www.archchicago.org/departments/ecumenical/Relations.htm>. Acesso em: 04 jan. 2017.

AMALADOSS, Michael. O Deus de todos os nomes e o diálogo inter-religioso. Cadernos de Teologia Pública 1o. São Leopoldo: Instituto Humanitas da UNISINOS, 2005.

AMALADOSS, M; TEIXEIRA, F. John Hick e o pluralismo religioso - Entrevista para a revista IHU On-Line. 2012. Disponível em: <http://www.ihu.unisinos.br/noticias/506496john-hickeopluralismo-religioso $>$. Acesso em: 15 jan. 2017.

ARIARAJAH, S. Wesley. Hindus and Christians: A Century of Protestant Thought. Grand Rapids: Eerdmans, 1991.

ARIARAJAH, S. Wesley. Interfaith Dialogue.In: LOSSKY, Nicholas, MIGUEZ-BONINO, José, POBEE, John, STRANSKY, Tom, WAINWRIGHT, Geoffrey, WEBB, Pauline (Orgs.).

Dictionary of the Ecumenical Movement. 2nd edition. Geneva: WCC, 2002. Disponível em <http://www.oikoumene.org/en/resources/documents/wcc-programmes/interreligiousdialogue-and-cooperation/interreligious-trust-and-respect/ecumenical-dictionary-interfaithdialogue >. Acesso em: 15 jan. 2017.

ARIARAJAH, S. Wesley. Not Withouth My Neighbour - Issues in Inter-Religions Relations. Geneva: WCC Publications, 1999.

ARIARAJAH, S. Wesley. The Bible and the People of Other Faiths. Geneva: WCC Publications, 1985.

BARRA, Suely Ribeiro. Hipótese pluralista de John Hick. A sua contribuição para o diálogo inter-religioso.Tese de Doutorado (Ciência da Religião). Juiz de Fora: Programa de Pós-Graduação em Ciência da Religião da Universidade Federal de Juiz de Fora, 2014. 
BERNHARDT, Reinhold. Teologia da trindade como fundamento de uma teologia protestante das religiões. Estudos Teológicos: São Leopoldo, v. 44, n.2, 2004, p. 58-72.

BRAATEN, Carl. Paul Tillich e a tradição cristã.In: TILLICH, Paul. Perspectivas da teologia protestante nos séculos XIX e XX. São Paulo: ASTE, 1986

CALDAS FILHO, C. R. Justificação pela fé no pensamento de Lutero e hoje: uma introdução.

Horizonte: Belo Horizonte, v. 14, n. 44, out./dez./2016, p. 163-1266. Disponível em:

<file://C:/Users/Home/Downloads/12442-49375-1-PB\%2O(1).pdf>.

CHUNG, Paul. Karl Barth and Inter-Religious Dialogue. Asia Journal of Theology:

Bangalore,v. 15, n.2, 2001.

CHURCH OF SOUTH INDIA. Disponível em: <http://www.csisynod.com/>. Acesso em: 15 jan. 2017.

CONGREGAÇÃO PARA A DOUTRINA DA FÉ. Artigo ilustrativo da Notificação a propósito do livro de Jacques Dupuis: "Para Uma Teologia Cristã Do Pluralismo Religioso". Disponível em: < http://www.vatican.va/roman_curia/congregations/cfaith/documents/rc_con_cfaith_doc_20 010312_dupuis-2_po.html>. Acesso em: 15 jan. 2017.

DUPUIS, Jacques. Verso una teologia Cristiana del pluralismo religioso. Brescia: Queriniana, 1999.

FUKAI, Tomoaki. Paul Tillich - Journey to Japan in 1960. Berlin: Gruyter, 2013.

GEFFRÉ, Claude. De Babel a Pentecostes. Ensaios de teologia inter-religiosa. São Paulo: Paulus, 2013.

GOUVEA, Ricardo Quadros. Esboços de teologia filosófica. Esforços para um desnudamento. São Paulo: Fonte, 2014.

HICK, John. Teologia cristã e o pluralismo religioso. O arco-íris das religiões. São Paulo: Attar, 2005.

HASTINGS, John Thomas. Kitamori Kazoh. In: SUNQUIST, Scott W. A Dictionary of Asian Christianity. Grand Rapids: Eerdmans, 2001. p. 445-446.

IHU - Instituto Humanitas da Unisinos. John Hick e o Pluralismo Religioso. Entrevista com Michael Amaladoss e Faustino Teixeira, a propósito da morte de John Hick. IHU On-Line 2012. Disponível em: <http://www.ihu.unisinos.br/noticias/506496-john-hickeopluralismoreligioso >. Acesso em: 15 jan. 2017.

INSTITUTE OF SLAMIC STUDIES. Mcgill University. Disponível em: $<$ http://www.mcgill.ca/islamicstudies >. Acesso em: 28 mar. 2017.

KAZOH, Kitamori. Theology of the Pain of God. Richmond: John Knox Press, 1965.

KNITTER, Paul F. Jesus e os outros nomes. Missão cristã e responsabilidade global. São Bernardo do Campo: Nhanduti Editora, 2010. 
KOYAMA, Kosuke. Three Mile An Hour God. London: SCM Press, 1979.

KOYAMA, Kosuke. Water Buffalo Theology. $2^{\text {nd }}$ edition. Maryknoll, New York: Orbis Books, 1999.

LOSSKY, Nicholas; MIGUEZ-BONINO, José; POBEE, John; STRANSKY, Tom; WAINWRIGHT, Geoffrey; WEBB, Pauline (Orgs.). Dictionary of the Ecumenical Movement.2nd Edition. Geneva: WCC, 2002.

MACHADO, Kleber de Oliveira. A hipótese pluralista de John Hick: pressupostos filosóficos e teológicos da visão fundamental hickiana. Dissertação de Mestrado (Ciências da Religião). São Paulo: Programa de Pós-Graduação em Ciências da Religião da Universidade Presbiteriana Mackenzie, 2009.

MALANKARA MAR THOMA SYRIAN CHURCH. Disponível em: <http://marthoma.in/>. Acesso em: 24 jan. 2017.

NEWBIGIN, Lesslie. O evangelho em uma sociedade pluralista. Viçosa: Ultimato, 2016.

PANASIEWICZ, Roberlei. Cristo como universal concreto: uma leitura da visão cristológica de Claude Geffré e sua disposição para com o diálogo inter-religioso. Perspectiva Teológica: Belo Horizonte,v. 41, n. 113, 2009, p. 87-98.

PANASIEWICZ, Roberlei. Pluralismo religioso contemporâneo. Diálogo inter-religioso na teologia de Claude Geffré. $2^{\mathrm{a}}$ edição. Belo Horizonte: Editora PUC Minas. São Paulo:

Paulinas, 2010.

PANIKKAR, Raimon. Hinduísmo e Cristianismo.In: VV AA. Ecumenismo das religiões. O catolicismo obrigado a sair do seu gueto. Petrópolis: Vozes, 1971a.

PANIKKAR, Raimon. Toda religião autêntica é caminho de salvação. In: VV AA.

Ecumenismo das religiões. O catolicismo obrigado a sair do seu gueto. Petrópolis: Vozes, 1971b.

PANNIKAR, Raimundo. The Unknown Christ of Hinduism. Towards an Ecumenical Christophany. 2nd Edition. Maryknoll, New York: Orbis Books, 1981.

PIERIS, Aloysius. Viver e arriscar. Estudos inter-religiosos comparativos a partir de uma perspectiva asiática. São Bernardo do Campo: Nhanduti, 2008.

RAHNER, Karl. Religião absoluta? In: VV AA. Ecumenismo das religiões. O catolicismo obrigado a sair do seu gueto. Petrópolis: Vozes, 1971.

RIBEIRO, Claudio de Oliveira. Pluralismo e libertação. São Paulo: Paulinas, 2014.

RIBEIRO, Claudio de Oliveira. Religiões e salvação: indicações para o diálogo inter-religioso na teologia de Paul Tillich. Numen: Juiz de Fora, v. 3, n. 2, 2000, p. 31-46.

RIBEIRO, Osvaldo Luiz. Esboços de teologia crítica. Reflexões no caminho da superação da teologia clássica. São Paulo: Fonte Editorial, 2013. 
SEMINA VERBI. Apologia de Justino o Mártir 1, 44-46. 2, 7.13. Disponível em: $<$ https://seminaverbi.wordpress.com/2009/o9/25/semina-verbi-en-las-apologias-de-sanjustino/>. Acesso em: 14 jan. 2017.

SMITH, Wilfrid Cantwell. O sentido e o fim da religião. São Leopoldo: Sinodal, 2006.

SONG, Choan Seng. Theology from the womb of Asia. New York, Maryknoll: Orbis Books, 1986

TEIXEIRA, Faustino. Dialogo de pássaros. Nos caminhos do dialogo inter-religioso. São Paulo: Paulinas, 1993.

TEIXEIRA, Faustino. Buscadores do dialogo itinerários inter-religiosos. São Paulo: Paulinas, 2012.

TEIXEIRA, Faustino. Cristianismo e diálogo inter-religioso. São Paulo: Fonte, 2014.

TEIXEIRA, Faustino. O dialogo inter-religioso como afirmação da vida. São Paulo: Paulinas, 1997.

TEIXEIRA, Faustino. O pluralismo inclusivo de Jacques Dupuis. 2010. Disponível em: <http://fteixeira-dialogos.blogspot.com.br/2010/o4/o-pluralismo-inclusivo-de-jacques.html>. Acesso em: 10 jan. 2017.

THOMAS, M. M. Risking Christ for Christ's Sake: Towards an Ecumenical Theology of Pluralism. Geneva: WCC, 1987.

TILLICH, Paul. The Future of Religions. New York: Harper \& Row, 1966.

VON SINNER, Rudolf. Confiança e convivência. Reflexões éticas e ecumênicas. São Leopoldo: Sinodal, 2007.

WCC - WORLD COUNCIL OF CHURCHES. Disponível em:

$<$ https://www.oikoumene.org/pt>. Acesso em: 10 jan. 2017.

WCC - WORLD COUNCIL OF CHURCHES - Ecumenical considerations for dialogue and relations with people of other religions, 2004. Disponível em:

$<\mathrm{http}$ //www.oikoumene.org/en/resources/documents/wcc-programmes/interreligiousdialogue-and-cooperation/interreligious-trust-and-respect/ecumenical-considerations-fordialogue-and-relations-with-people-of-other-religions $>$. Acesso em: 15 jan. 2017.

YONG, YI JEONG. Marginality: The Key to Multicultural Theology. Minneapolis: Fortress Press, 1995. 